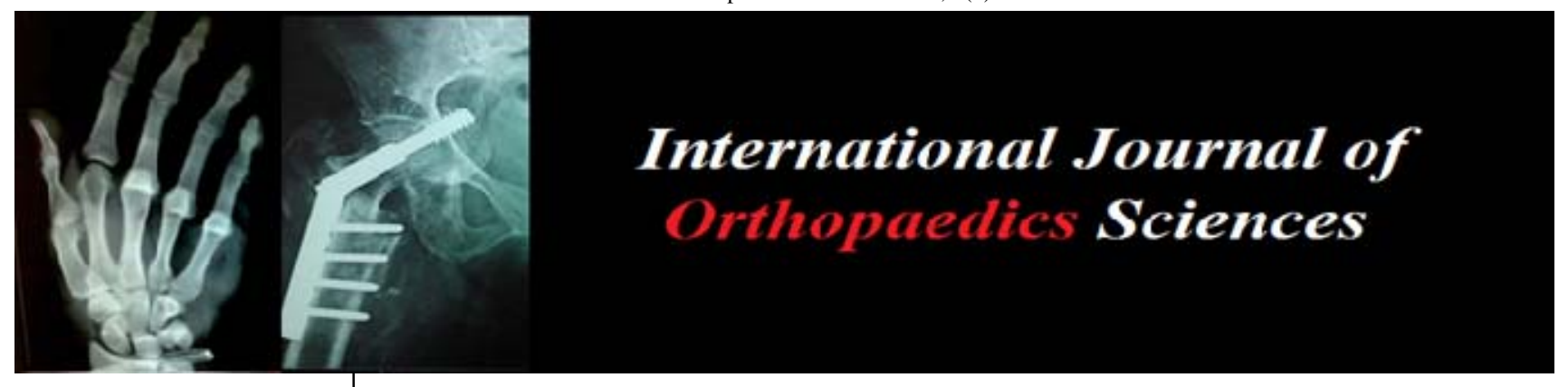

E-ISSN: 2395-1958 P-ISSN: 2706-6630 IJOS 2020; 6(3): 873-880 (C) 2020 IJOS

www.orthopaper.com Received: 20-05-2020 Accepted: 25-06-2020

Dr. Ravindra Prasad Senior Resident, Department of Orthopedics, RIMS, Ranchi, Jharkhand, India

Dr. LB Manjhi

Professor, Department of Orthopedics, RIMS, Ranchi, Jharkhand, India
Corresponding Author: Dr. Ravindra Prasad Senior Resident, Department of Orthopedics, RIMS, Ranchi, Jharkhand, India

\section{Evaluation of outcome of fracture of adult diaphyseal forearm bones treated by nailing and plating}

\author{
Dr. Ravindra Prasad and Dr. LB Manjhi \\ DOI: https://doi.org/10.22271/ortho.2020.v6.i3m.2297
}

\begin{abstract}
Introduction: Fracture of both bones forearm in adults occupy a large field of modern traumatology. Maintenance of radial bow, regaining length, good apposition and alignment without malrotation is essential to restore good range of motion of forearm.

Aim: to compare functional and radiographic results of plate osteosynthesis to IM nailing in treatment of diaphyseal forearm fracture in adults.

Method: a prospective study comprising of 30 patients. 15 patients treated with open reduction and internal fixation using $3.5 \mathrm{~mm}$ DCP and 15 patients by IM nailing using 316L SS Talwarkar square nailing by closed or mini open reduction.

Result: mean age of patients was 36.4 years (range 20 to 58 years), most fractures were of type 22A3 as per AO/OTA classification. Average operative time was 83 minutes and 64 minutes in plating and nailing respectively. 2 cases of infection each in plating and nailing was seen which were superficial. Mean time of union in plating group was 12.8 weeks (range 10-18 weeks) with union achieved in all cases and DASH score of 14.7(range 4.1-33.3) with excellent functional results in $73.3 \%$ cases. In nailing group, 2 cases of non-union was seen (13.3\%) with mean time of union 14.6 weeks (range 1122 weeks) and DASH score of 18.5(range 5-45) with excellent functional results in 53.3\% cases. Conclusion: We conclude that open reduction and internal fixation with dynamic compression plating is gold standard for treating diaphyseal forearm fracture in adults as it provides rigid fixation, restores forearm stability earlier and has negligible complications.
\end{abstract}

Keywords: diaphyseal forearm fracture, dynamic compression plating, square nailing

\section{Introduction}

Forearm plays an important role in positioning of the hand in space and supination through the proximal and distal radioulnar joint. These fractures can be regarded as articular fracture as slight deviation or malalignment will significantly decrease the forearm rotational amplitude by impairing the positioning and hand function. The main goal of treatment of fractures of shaft off ulna and radius is to recover painless function of the forearm and upper extremity. Anatomic reduction of the ulna and radius is therefore desirable whenever achievable to adequately restore the spatial relationship between these bones followed by rigid fixation to allow early range of motion while healing occurs.

Among the various modes of internal fixation devices, plates and screws is the most widely used method of treatment for unstable forearm fractures. A variety of plates for internal fixation of forearm shaft include DCP (dynamic compression plate), LC-DCP (limited contact), LCP (locking compression) and semi tubular plates but the most effective type of plate has not been defined. Application of a plate can disrupt the periosteal blood supply and necessitates skin incision that may be unsightly. There is also an increased risk of fracture if the implant is removed. Use of intramedullary devices to stabilize fractures of forearm predates nailing of femur and tibia. Its slower technical development appears to be due to anatomic problems of the radius, the interdependence of the two bones, and the strong torque loads from pronator and supinator. In 1959, Dr Talwarkar designed Square nails for fixation of forearm fractures which has gained significant popularity. Intramedullary nailing comes with its own sets of advantages and disadvantages. Good outcomes are reported for pediatric forearm fractures. Less favorable results have been shown for adult forearm fractures, since 
adequate reduction is difficult to achieve and only marginal rotational stability is provided. However, chances of infection are significantly decreased as incision is smaller and it uses least amount of periosteal stripping. It also has lower refracture rates after implant removal.

The purpose of this study is to assess and compare in adults the radiographic and functional results of Intramedullary nailing (Talwarkar Square nail) to that of the plate and screw fixation using dynamic compression plate in treating both bone forearm fracture.

\section{Material and Methods}

The study was conducted in Rajendra Institute of Medical Sciences, Ranchi after getting clearance from the Ethics committee. All study participants gave written informed consent for participation in this study. The study was conducted from October 2015 to October 2017 on patients admitted from the emergency department or presenting in the outpatient department of the hospital. A total of 30 patients were evaluated during this period who met the inclusion and exclusion criteria.

\section{Inclusion Criteria}

1. Age more than 18 years

2. Diaphyseal fracture both bone forearm (all close and open Gustilo type 1)

3. Comminuted fractures

4. Osteoporotic fractures

5. Segmental fractures

\section{Exclusion Criteria}

1. Skeletal immaturity

2. Open fracture (Gustilo type 2 and 3)

3. Presence of neurovascular deficit

4. Fractures in proximal and distal metaphysis

5. Patients with associated injuries such as distal radioulnar joint (DRUJ) disruption and other fractures in the same limb

6. Patients with head injury

7. Refusal to provide informed consent

Out of 30 patients in the study, 15 patients were treated by Open reduction and internal fixation with Dynamic compression plating and 15 patients by Intramedullary nailing using Talwarkar Square nailing. Allocation of fracture to each treatment group was done by random selection.

All the cases were evaluated post-operatively through clinical and radiological methods at 2 weeks, 6 weeks and monthly thereafter for up to 6 months for any morbidity.

Assessment of the patients was done based on a proforma containing all the necessary information regarding

1. Personal details: age, sex, address, occupation

2. Mode of trauma: RTA, fall, assault, others

3. Type of fracture

4. Surgical procedure carried out with duration of surgery

5. Radiological outcome

6. Functional outcome

7. Range of movement of forearm

8. Development of surgical complications

\subsection{Surgical Technique}

For Open reduction and plate fixation using DCP, patients are placed in supine position under regional (brachial block) or general anaesthesia, with the operative arm placed on a radiolucent arm board. Field is prepped up to the level of mid arm and a sterile tourniquet in the form of esmarch bandage is applied.

For Ulna, incision may be performed with the elbow flexed on a hand table, thereby holding the forearm in a vertical position. The skin incision is centered over the fracture site and over the subcutaneous ulna. The underlying fascia is then incised and the interval between ECU and FCU developed. Plates are placed either onto the dorsal aspect of the ulna underneath ECU or the volar aspect under FCU. Plate placement on the subcutaneous border of the ulna should be avoided as it will become symptomatic and place soft tissue healing at risk.

Exposure of the radius from the bicipital tuberosity to the distal articular surface of the radius can be achieved using the anterior approach also known as volar approach of Henry. Skin incision is performed on a line connecting the lateral aspect of the biceps tendon proximally with the radial styloid distally. Dissection proceeds between brachioradialis and the PT proximally and brachioradialis and FCR distally. Access to the proximal third of the radial shaft is gained by releasing the supinator muscle from the radius. The middle third of radial shaft is accessed by pronating the forearm and incising the radial origins of the PT and FDS distal to the supinator muscle. The distal third of radius is accessed by sweeping the FPL ulnarly and exposing the underlying PQ muscle. By supinating the forearm, the PQ can be released from its radial origin and reflected ulnarly.

In both bone forearm fracture, the sequence of fixation is usually determined by the amount of fracture comminution. If both fractures are simple, either fracture may be fixed first. However, ulna is frequently fixed initially because of its straight geometry.

For radius, fracture site is exposed using anterior Henry approach by preserving as much of the attached soft tissues as possible. Reduction of fracture fragment is performed using pointed reduction forceps. Forearm supination and pronation also aids in achieving reduction.

For plate fixation, it is generally recommended that screws should engage at least six cortices on each side of the fracture. For this purpose, a six- to eight-hole 3.5mm DCP has been used. With fracture in reduced position, plate is held in position with two clamps. Plate is fixed to the shaft on one side and fracture is kept reduced by holding opposite shaft fragment with a single clamp. The opposite shaft fragment is then fixed to the plate with a screw going through an eccentrically drilled hole, thereby achieving interfragmentary compression. The remaining screws on the side of the initially stabilized shaft segment are then placed in a neutral position, whereas an additional compression screw hole may be drilled in the opposite shaft segment. Prior to final screw seating, the initial compression screw will have to be loosened and the second compression screw tightened, thereby providing further compression at fracture site. The final compression screw is then retightened and a third neutral screw is placed.

Fixation of ulna fracture is similarly done using direct dorsal approach.

After completion of fracture fixation, wound is irrigated and the tourniquet released to obtain hemostasis. This reduces the risk of subsequent hematoma. A negative suction drain is applied over the radial wound and the skin closure done 
with interrupted non absorbable monofilament suture stitches. An antiseptic dressing is then applied over it.

Postoperative Care: After operative fixation of fracture both bone forearm, clinical monitoring of compartment syndrome is done. Elevation of operative extremity is done for first 72 hours after surgery to reduce swelling and improve pain.

Early range of motion of the elbow, wrist and fingers is encouraged as well as active pronation and supination. Suture removal is done at 2 weeks. Routine daily activities were permitted, but heavy work or sports activities was delayed until fracture union was observed radiologically and clinically.

For Intramedullary nailing using Square nail, 316 stainless steel Talwarkar Square nail were used for all patients for both radius and ulna fracture fixation. Nail diameter were $2.0 \mathrm{~mm}, 2.5 \mathrm{~mm}, 3.0 \mathrm{~mm}$ or $3.5 \mathrm{~mm}$, with nail lengths from 21 $\mathrm{cm}$ to $31 \mathrm{~cm}$ for all surgical procedure. Preoperative AP and lateral forearm radiographs of both the injured and the noninjured contralateral forearm were taken. The size of nails was estimated on the normal limb radiograph. The distance from the olecranon to the ulnar styloid was measured. Ulnar nail should be $1 \mathrm{~cm}$ shorter than this distance whereas radial nail should be $3 \mathrm{~cm}$ shorter. Nail diameter is determined by measuring the isthmus.

Under general or regional anesthesia, the patients were positioned supine on the operating table with a radiolucent arm board. The shoulder was abducted and the elbow flexed 90 degrees for nailing of the ulna whereas for nailing of radius, the arm was extended. Field was prepped up to the level of mid arm and a sterile tourniquet in the form of Esmarch bandage is applied. Nailing of ulna was done first, thereby providing a more stable forearm for retrograde nailing of the radius. For ulna, a $1 \mathrm{~cm}$ longitudinal incision over the tip of olecranon is given. The triceps insertion is split and a starting point on the proximal ulna is created 5 to $8 \mathrm{~mm}$ from the dorsal cortex and $5 \mathrm{~mm}$ from the lateral cortex with the help of an awl. This allows insertion of a straight nail despite the lateral bow of the ulna, while avoiding the articular surface of the greater sigmoid notch. If an open reduction is performed, the medullary canal is reamed through the fracture site both proximally and distally. Reaming of the whole length of medullary canal is recommended especially in the distal segment of the ulna, as cancellous bone present at this level may interfere with nail advancement and lead to fracture distraction. The final nail diameter of size 0.5 to $1 \mathrm{~mm}$ smaller than the diameter of the isthmus after reaming was chosen. Reaming is only required in medullary canals that measure $3.5 \mathrm{~mm}$ or less. An ulnar nail of appropriate size was selected and loaded over a $\mathrm{T}$ handle. The nail was pushed free hand into the medullary canal of the ulna while fracture was kept reduced under $\mathrm{C}$ arm guidance. If close reduction failed, a mini open reduction was performed. The distal end of the nail was usually within $1 \mathrm{~cm}$ of the tip of ulna. The end of the nail was buried inside the olecranon. For the radius, a $2-\mathrm{cm}$ longitudinal incision just lateral to Lister tubercle is performed on the dorsal surface. After skin incision, careful blunt dissection is done to avoid injuring the sensory branch of the radial nerve. A low ridge between ECRB and ECRL is identified. The entry into the medullary canal was made with an awl, $1 \mathrm{~cm}$ proximal to the articular surface. The radius nail is loaded over the T-handle and pushed with the beveled edge of the radius nail sliding over the volar surface of the radius. The fracture was held reduced through close reduction under $\mathrm{C}$ arm guidance and nail advanced up to the proximal border of the bicipital tuberosity of the radius. Distally the nail was buried flush with the bone. If in any case the reduction was difficult to achieve, a mini open reduction was performed. After completion of the procedure, skin closure was done with non-absorbable monofilament interrupted suture and antiseptic dressing applied.

Postoperative Care: All patients were immobilized with an above elbow slab with elevation of the limb and asked to perform active finger movements. Movement of the thumb was especially checked for any injury to the EPL tendon during surgery. Suture removal was done at 2 weeks and another above elbow slab was applied until early radiographic healing can be observed. Thereafter, patients were allowed to use the affected extremity without weight bearing until solid radiographic healing has been achieved. All patients were prescribed physiotherapy for range of motion and strengthening exercises.

Follow Up: Patients were evaluated clinically and radiographically at 1, 2, 3 and 6 months after surgery till radiographic healing was seen. Fracture union was defined as the presence of bridging callus at the fracture site and disappearance of fracture gap in AP and Lateral radiography. The patients were also evaluated clinically for fracture site tenderness and pain on rotation. Those fractures which required more than 6 months to unite and had no additional operative procedure performed were classified as Delayed union. Those fractures which failed to unite without another operative procedure were classified as Nonunion. At the final assessment, degree of forearm rotation was measured with a goniometer.

Functional results were assessed using Anderson et al criteria. Patient related outcome was assessed with the Disability of Arm, Shoulder, Hand questionnaire (DASH). Anderson et al criteria.

\section{Result and Discussion}

Age distribution: The age of the patients in the study ranged from 20 years to 58 years. The mean age of study participants was 36.4 years. The mean age of Males in the Plating group was 35.2 years with a Range of 20-55 years while the Mean age of Females was 41.5 years with a Range of 32-49 years. In the Nailing group, the Mean age of Males was 32.2 years with a Range of 21-49 years while that of Females was 41.2 years with a Range of 30-48 years. Most of the fractures occurred in the age group of 31-40 years (a total of 11 participants out of 30 constituting to $36.7 \%$ ).

Sex distribution: Most of the forearm fractures occurred in Males (19 out of a total 30 participants in the study amounting to $63.3 \%$ ) While in Females, it was 36.7\%. Other clinical studies also show without exception that forearm fractures occur predominantly in male patients.

Mode of injury: The most common mode of injury was Fall which was the cause of fracture in over half of the patients (17 cases out of 30,56.7\%). The second most common cause was road traffic accidents accounting for one-third of cases followed by assault which was the cause in only $10 \%$ of the cases. 
Side of injury: In this study, both right and left upper limbs were found to be equally involved. Pattern of Fracture: Transverse and Short oblique pattern were found to be most common fracture pattern in this study with both occurring in equal frequency (13 each out of $30,46.7 \%$ ). In the Plating group, frequency of Transverse and Oblique fractures was $46.7 \%$ and $40 \%$ respectively whereas in the Nailing group, they were $40 \%$ and $46.7 \%$ respectively. Cases of Spiral and Comminuted fractures were $6.67 \%$ each.

Type of Fracture: Most of the fractures were of Type 22A3 according to AO/OTA classification system. They constituted over half of the cases (16 out of 30,53.3\%). In the Plating group, these fracture types constituted $60 \%$ of the cases whereas in the Nailing group, these were $46.7 \%$. Next in frequency were Type 22B3 which occurred in about one-third of cases. Type $\mathrm{C}$ fractures (comminuted or segmental) were found to be least common.

Duration of Surgery: The average operative time for Plating was 83 minutes while in case of Nailing, it was significantly less that is 64 minutes.

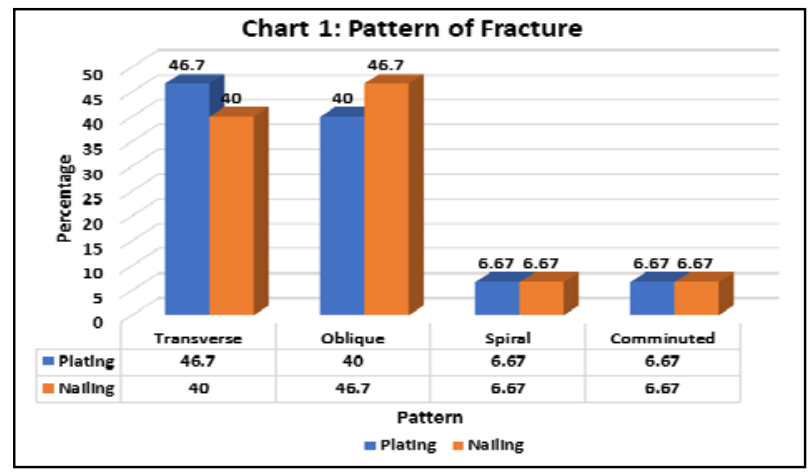

Chart 1: Pattern of Fracture

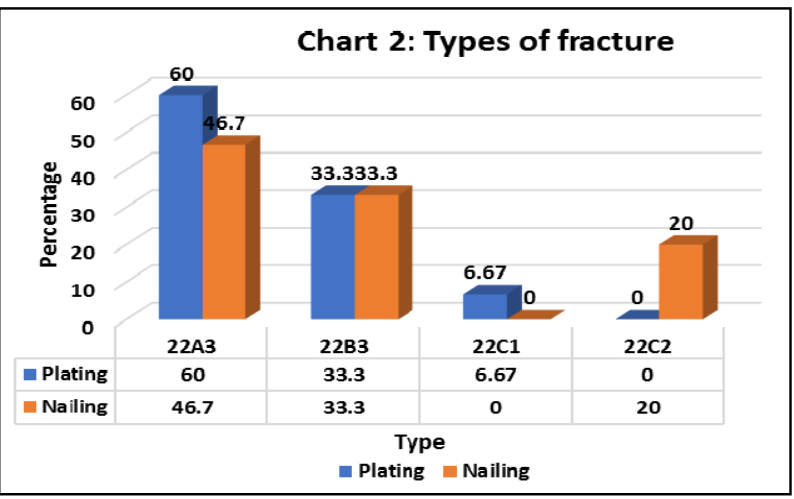

Chart 2: Types of Fracture

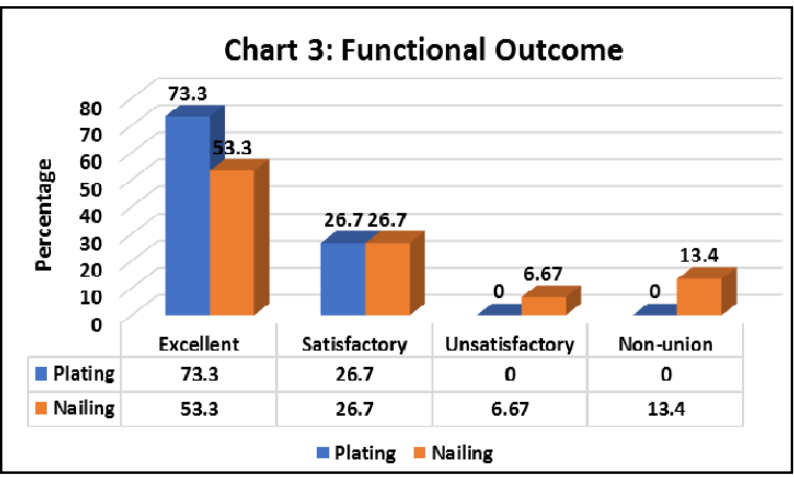

Chart 3: Functional of Outcome
Table 1: Time of fracture union

\begin{tabular}{|c|c|c|c|}
\hline Method & N & Range (week) & Mean (week) \\
\hline Plating & 15 & $10-18$ & 12.8 \\
\hline Nailing & 13 & $11-22$ & 14.6 \\
\hline Total & 28 & $10-22$ & 13.7 \\
\hline
\end{tabular}

Table 2: DASH Score

\begin{tabular}{|c|c|c|c|}
\hline Method & N & Range & Mean \\
\hline Plating & 15 & $4.1-33.3$ & 14.7 \\
\hline Nailing & 15 & $5-45$ & 18.5 \\
\hline Total & 30 & $4.1-45$ & 16.6 \\
\hline
\end{tabular}

Table 3: Movement of Forearm

\begin{tabular}{|c|c|c|c|c|}
\hline \multirow{2}{*}{$\begin{array}{c}\text { Movement } \\
\text { (degree) }\end{array}$} & \multicolumn{2}{|c|}{ Plating } & \multicolumn{2}{c|}{ Nailing } \\
\cline { 2 - 5 } & Range & Mean & Range & Mean \\
\hline Supination & $45-75$ & 65.2 & $38-74$ & 60.7 \\
\hline Pronation & $60-86$ & 77.5 & $48-86$ & 69.2 \\
\hline Elbow Flexion & $110-140$ & 133.3 & $118-145$ & 133.4 \\
\hline Wrist Flexion & $60-82$ & 72.8 & $45-82$ & 70.5 \\
\hline Wrist Extension & $52-67$ & 58.9 & $38-63$ & 56.1 \\
\hline
\end{tabular}

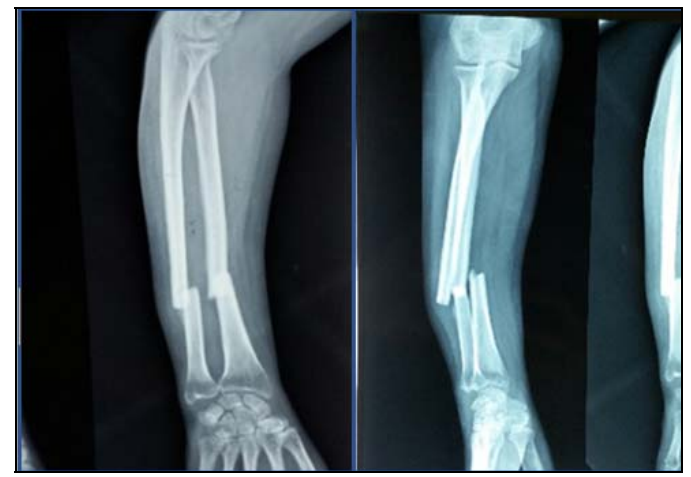

Fig 1: Preoperative Radiograph (selected for Plating)

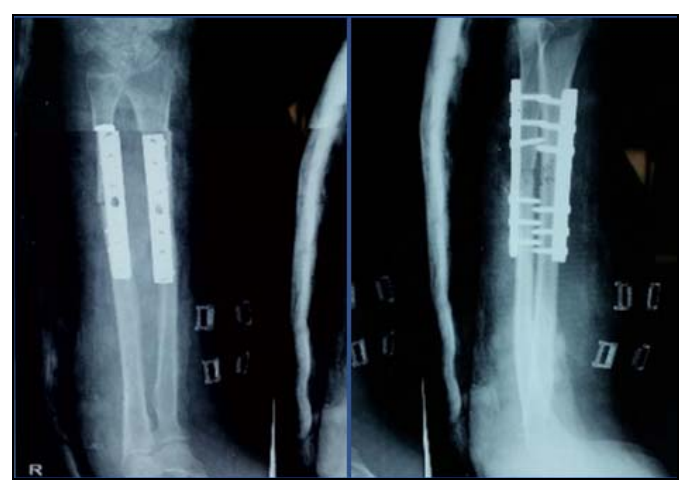

Fig 2: Postoperative Day 1

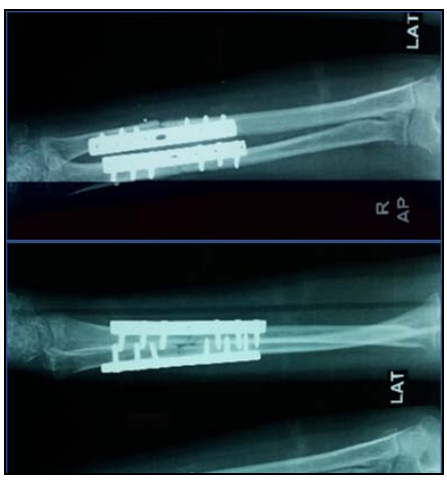

Fig 3: Postoperative 10 weeks 


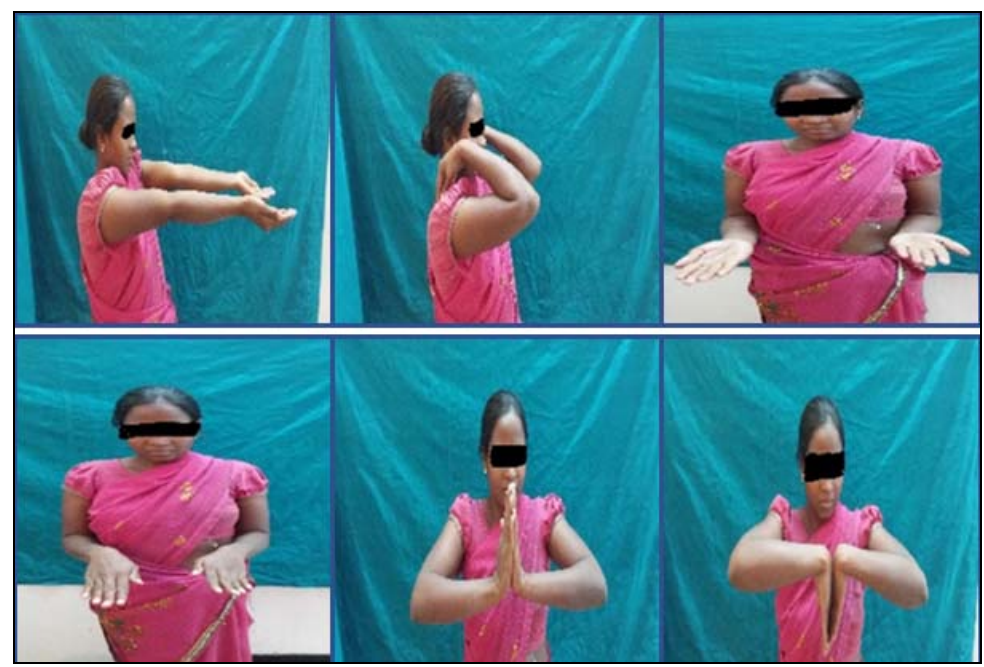

Fig 4: Functional results of Plating

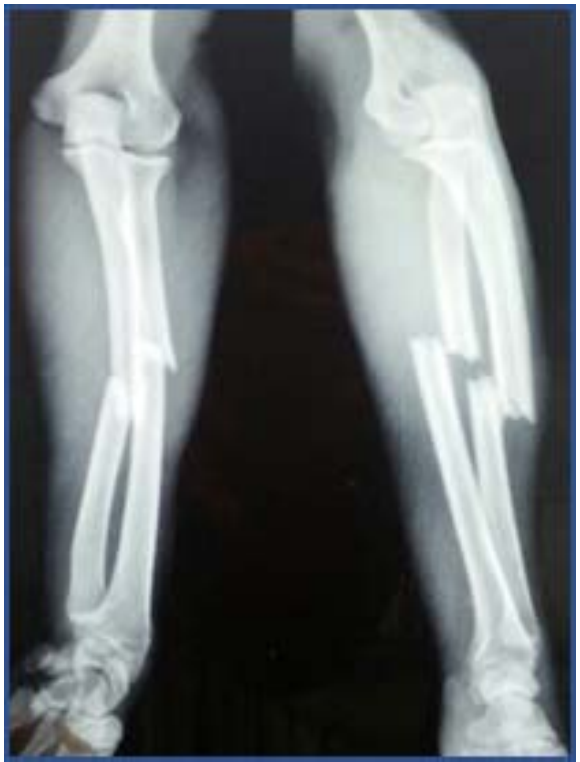

Fig 5: Preoperative radiograph (selected for Nailing)

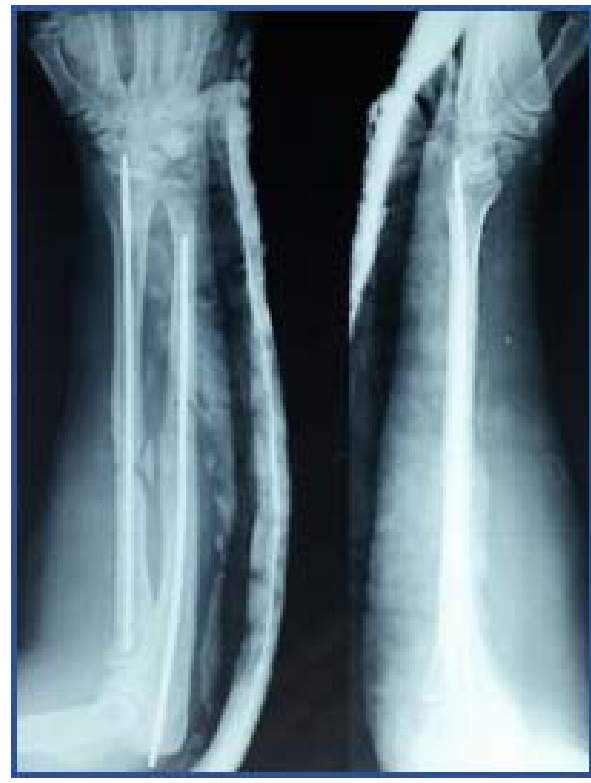

Fig 6: Postoperative Day 1

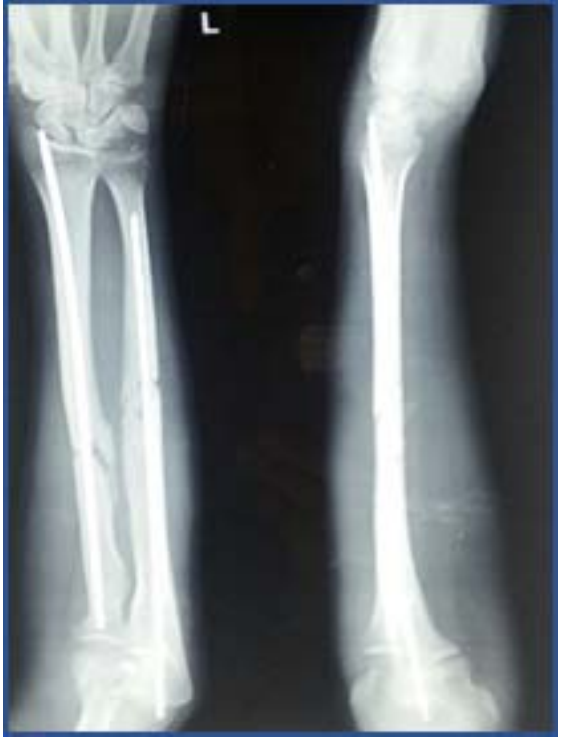

Fig 7: Postoperative 10 weeks

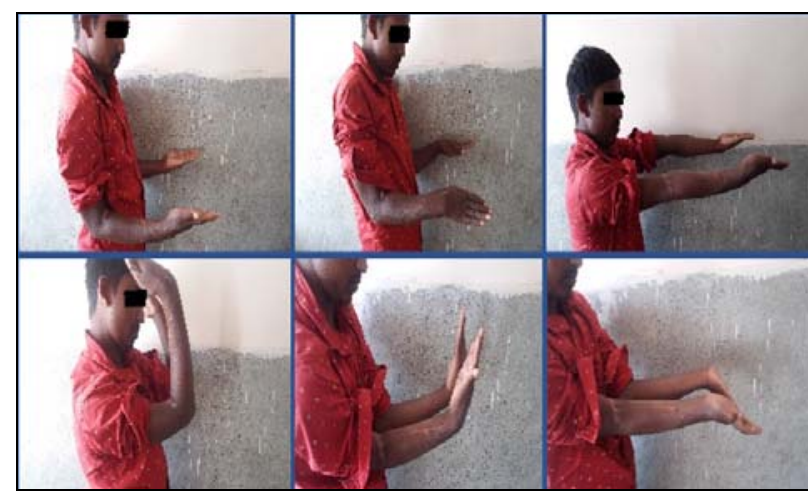

Fig 8: Functional results of Nailing

\section{Post-operative complication:}

Infection: Infection has been reported to occur in between $0 \%$ to $3 \%$ of forearm fractures. Anderson et al. reported an infection rate of $3 \%$ in 330 fractures of the forearm treated with plate and screw fixation. In the present study, there were 2 cases each of infection in the Plating and Nailing group, both of which were superficial. All the cases responded well with broad spectrum intravenous antibiotics 
and regular antiseptic dressing. No cases of deep infection were seen.

Nerve palsy: The most frequently injured nerve during operative treatment of forearm fractures is the radial nerve or its terminal motor branch, the posterior interosseous nerve. However, in the present study, no cases of nerve palsy were seen.

Compartment syndrome: It is a potentially devastating complication of fracture both bones forearm. The incidence of forearm compartment syndrome has been reported to be $2 \%$ after open reduction and internal fixation. However, no such cases were seen in this study.

Radioulnar Synostosis: Complete radioulnar synostosis with a solid bony bridge occurs in $1 \%$ to $6 \%$ of forearm fractures. Hadden et al. reported 6 patients with synostosis in a series of 108 patients with forearm fractures. Chapman et al. reported a single case of synostosis developing after operative treatment of forearm fractures in 88 patients. Both bone fractures affecting the radius and ulna at the same level in the forearm, along with significant comminution have been found to be associated with this complication. However, in this study no cases of synostosis were found to occur.

Non-union: Nonunion rates after plate and screw fixation ranges between $0 \%$ to $10 \%$. Nadeem A Lil et al. conducted study on intramedullary nailing using Talwarkar Square nail in adult forearm fractures and reported $8.8 \%$ cases of nonunion. Non-unions are generally secondary to inadequate biomechanics, inadequate biology or both. Inadequately followed principles of fixation prevents primary bone healing and possibly results in nonunion. Too much rigidity in a construct or a fracture gapping may lead to inadequate healing. Factors affecting the biomechanics of fracture healing include selection of a plate of inadequate length, inadequate plate placement, and screw insertion too close to the fracture site when using compression plating. High energy injuries with open fractures, severe comminution and excessive soft tissue stripping increases the risk of poor vascularity at the fracture site inhibiting healing. Furthermore, around one-third of nonunion occur in the presence of a deep surgical site infection. In cases of intramedullary nailing, causes of non-union include inadequate anatomical fixation and thinner size of the nails which may not be rigid enough to withstand torsional, rotational and angulating forces of forearm muscles with more risk of distraction at the fracture site resulting in nonunion. In the present study, 2 cases of non-union was observed in the Nailing group amounting to $13.3 \%$ of the cases whereas no case of non-union was seen in the Plating group. Hertel et al. reported results of 132 patients who were treated with small DCP and only 2 cases of non-union and 2 cases of delayed union were seen in their patients.

Time of Fracture union: The mean time of union in the Plating group was 12.8 weeks with a range between 10-18 weeks. In the Nailing group, mean time for union was 14.6 weeks with a range of 11- 22 weeks. Two cases of nonunion were seen in the Nailing group whereas all the fractures united treated by ORIF with compression plating. Lee et al. reported on 38 forearm fractures in adults treated with intramedullary nailing and healing was observed in all except one fracture at a mean of 14 weeks. Visna et al also reported a mean union time of 14 weeks in cases of intramedullary nailing. Ozkaya et al. compared both bone fractures treated by Nailing and Plating and found that IM nailing healed on an average in 10 weeks as compared to 14 weeks after plate and screw fixation.

DASH Score: The mean DASH score in the Plating group was found to be 14.7 with a Range of 4.1 to 33.3. In the Nailing group, mean DASH score was 18.5, with a Range of 5 to 45. Ozkaya et al in his comparative study between Plating and IM nailing found no significant difference in DASH score between these two groups. Droll et al. investigated functional outcome after Plating of 30 patients and reported a loss of $30 \%$ by DASH.

Movement of Forearm: In the Plating group, mean forearm supination was 65.2 degree and mean forearm pronation was 77.5 degree. Mean elbow flexion was found to be 133.3 degree, mean wrist flexion 72.8 degree and mean wrist extension 58.9 degree. In the Nailing group, mean forearm supination was 60.7 degree and mean pronation was 69.2 degree. Mean elbow flexion was 133.4 degree, mean wrist flexion 70.5 degree and mean wrist extension 56.1 degree. Droll et al compared injured arms to uninjured arms, and found that injured arms had reduced strength of forearm pronation (70\%) compared to that of the normal arm, reduced forearm supination (68\%), reduced wrist flexion (84\%), reduced wrist extension (63\%) and reduced grip strength. Goldfarb et al. analyzed the functional score in 23 patients having both bone forearm fracture and found a mean 10- degree reduction in pronation and grip strength in the forearm.

Functional Outcome: Functional results were assessed using Anderson et al. criteria which was based on the state of union, loss of flexion and extension at the wrist joint and loss of forearm supination and pronation as compared to that of the uninjured forearm. Functional forearm is very essential for an individual for social and economic thriving. Fracture of forearm bones may result in severe loss of function unless treated adequately. In addition to regaining length, apposition and axial alignment, achieving rotational alignment is necessary, if a good range of pronation and supination is to be restored. Rotation of the forearm depends on the ability of the radius to rotate around the ulna. Angulation of 10 degrees in the radius or ulna can result in a loss of 20 degrees of forearm rotation. With 20 degrees of angulation, significant restriction in passive movement of the forearm will occur. This is the reason that anatomical reduction with restoration of the normal curve of the radius and rigid fixation can provide the best results in forearm fractures. Malunion and nonunion occur more frequently because of difficulty in reducing and maintaining reduction of two parallel bones in the presence of the pronating and supinating muscles that have angulatory as well as rotational influences. Because of these factors, surgical management for displaced diaphyseal fractures in adults is generally accepted. Hence, Open reduction and internal fixation is the treatment of choice for the majority of the fractures of both bones forearm in adults. Good early reduction and rigid fixation restores forearm stability earlier and limits dead space produced as a result of shortening and malposition. While reducing the fracture, it is important to correct the angulation, radial bowing and rotational deformities. In our study, in the Plating group, union was achieved in all the patients and results were found to be excellent in $73.3 \%$ patients (11 out of 15 cases) and satisfactory in remaining $26.7 \%$ patients. No cases of non-union or failure was seen. Kirit et al. reported excellent outcome in 92\% cases of forearm fracture treated by compression plating. Roy and 
Sharma in their series of 37 cases treated by DCP reported excellent outcome in $78 \%$ cases. In the Nailing group, union was achieved in $86.6 \%$ cases (13 out of 15 patients). Results were found to be excellent in only $53.3 \%$ cases (8 out of 15) as compared to $73.3 \%$ seen in cases of Plating. Satisfactory results were obtained in $26.7 \%$ cases (4 out of 15 ) and unsatisfactory in $6.67 \%$ ( 1 out of 15 ). 2 cases of non-union $(13.3 \%)$ was also seen of which one was in radius and one in both radius and ulna. These cases were further treated with removal of the nail followed by compression plating supplemented by autogenous cancellous bone grafting using iliac crest. Street et al in his series of 103 cases of forearm fractures treated by Square nailing found excellent results in 83.5\% cases with a failure rate of $8.5 \%$. Gao et al. reported $72 \%$ excellent and $11 \%$ unacceptable results in a similar study. Ozkaya et al. reported $80 \%$ excellent, $10 \%$ good and $10 \%$ acceptable results in his series of 20 patients treated by IM nailing whereas Lee et al. reported $81 \%$ excellent results. By compression plating, the fracture united by primary bone healing. Fractures were fixed rigidly with their blood supply disturbed as little as possible. Under these conditions, resorption and bone formation occurred simultaneously. Fracture gaps are obliterated or diminished greatly by compression, hence capillaries are able to grow in to the medullary canal at an early stage in the healing process. Their integrity is protected by the rigidity of the fixation and thus the mesenchymal cells in a well oxygenated environment may readily differentiate into osteoblasts. In the present study, it was observed that though Plating required longer duration of surgery as compared to nailing, time taken for union was significantly shorter as compared to nailing and functional outcomes were also much better than those of nailing. Moreover, patients undergoing plate fixation did not required any form of external bracing. Intramedullary nailing has many advantages over open reduction and plate fixation which includes low incidence of infection, smaller scar, less blood loss and a shorter operative time with minimal surgical trauma. Another important advantage of Nailing is their stress-sharing behavior, which facilitates secondary periosteal callus formation. In our study, main complications of nailing were found to be due to improper nail size. The use of nails with too large diameter can cause iatrogenic fracture, while nails with too small diameter can cause rotational instability. There is risk of damage to the extensor pollicis longus tendon and the superficial branch of radial nerve at the point of entry of the nail. Preoperative planning and a cautious approach during surgery minimizes the rate of complications caused by inappropriate nail selection and incorrect surgical technique. Achieving anatomic reduction is also more difficult in intramedullary nailing than in open reduction. Post-operatively, additional immobilization of the patients managed with intramedullary nailing is required with a long arm splint or cast until early radiographic healing can be observed which may take up to 6 weeks. It also remains a downside of the procedure. We found in our study that fixation with Square nail is not rigid enough to withstand the torsional, rotational and angulating forces of the muscles of the forearm and hence prone to poor functional results.

\section{Conclusion}

Increased incidence of forearm bone fractures is probably related to increasing road traffic accidents and fall. Forearm fracture in adults is more common in third and fourth decade and occurs predominantly in males. Open anatomical reduction and internal fixation can be considered as a treatment of choice if no contraindications are there as it is important to maintain length, apposition, axial alignment and rotational alignment to restore good functional forearm. From our study, we conclude that Open reduction and internal fixation with Dynamic compression plate with strict adherence to surgical technique is gold standard method for treatment of diaphyseal forearm fractures in adults as it provides rigid fixation, restores forearm stability earlier and has negligible complications. Intramedullary nailing with Talwarkar Square nail though a simple method is associated with inferior results and more complications than compression plating and it should be done only in selected cases. Best indications for Intramedullary nailing in adult diaphyseal forearm fractures include 1. Incomplete soft tissue cover 2. Multi-segmental fractures 3. Multiple injuries 4. Patients with severe osteoporosis 5. Following non-union in plate fixation 6 . Pathological fractures. In all other cases, open reduction and internal fixation with Dynamic compression plate remains the method of choice.

\section{References}

1. Chapman MW, Gordon JE, Zissimos AG. Compression plate fixation of acute fractures of the diaphysis of the radius and ulna. J Bone Joint Surg Am. 1989; 71(2):159-169.

2. Richard MJ, Ruch DS, Aldridge JM $3^{\text {rd }}$. Malunions and nonunions of the forearm. Hand Clin. 2007; 23(2):235243.

3. Rao R. A prospective study of pediatric forearm bone fractures treated with closed intramedullary square nailing. J Orthop Surg. 2009; 6(1):12

4. Roberts JW, Grindel SI, Wang M. Biomechanical evaluation of locking plate radial shaft fixation: unicortical locking fixation versus mixed bicortical and unicortical fixation in a sawbone model. J Hand Surg Am. 2007; 32(7):971-5.

5. Stevens CT, Ten Duis HJ. Plate osteosynthesis of simple forearm fractures: LCP versus DCP plates. Acta Orthop Belg. 2008; 74(2):180-183.

6. Henle P, Ortiieb K, Kuminack K. Problems of bridging plate fixation for the treatment of forearm shaft fractures with the locking compression plate. Acta Orthop Trauma Surg. 2011; 131(1):85-91.

7. Snow M, Thhompson G, Turner PG. A mechanical comparison of the LCP and the Low-contact DCP in an osteoporotic bone model. J Orthop Trauma. 2008; 22(2):121-5.

8. Daruwalla JS. A study of radioulnar movement following the fracture of the forearm in children. Clin Orthop. 1979; 139:114-120.

9. Barry M, Paterson JMH. Flexible intramedullary nails for fractures in children. J Bone Joint Surg Br. 2004; 86:947-53.

10. Street DM. Intramedullary forearm nailing. Clin Orthop Relat Res. 1986; 212:219-30.

11. Sage FP. Medullary fixation of fractures of the forearm. J Bone Joint Surgery Am. 1959; 41:1489-525.

12. Talwarkar AK, Talwarkar CA. Internal fixation of fractures of radius and ulna in adults with Talwarkar intramedullary nails. Indian J Orthop. 1967; 1(1):26-30. 
13. Anderson LD, Sisk D, Tooms RE, Park WI III. "Compression plate fixation in acute diaphyseal fractures of radius and ulna”. J Bone Joint Surg AM 1975; 57:287-97.

14. Chapman MW, Gordon JE, Zissimos AG. "Compression plate fixation of acute fractures of the diaphyses of the radius and ulna”. J Bone Joint Surg Am 1989:71:159-69.

15. Ross ER, Gourevitch D, Hasting GW. Retrospective analysis of plate fixation of diaphyseal fractures of forearm bones". Injury. 1989; 20(4):211-4.

16. Andrew $\mathrm{H}$ Crenshaw Jr, Edward A. Fractures of forearm treated with plates and screws. CAMPBELL'S Operative Orthopaedics. Vol 3. 11 edition pg:3428-31.

17. Grace TG, Eversmann WW Jr. Forearm fractures: treatment by rigid fixation with early motion. J Bone Joint Surg Am. 1980; 62(3):433-8.

18. Smith JE. Internal fixation in the treatment of fractures of the shafts of the radius and ulna in adults; the value of delayed operation in the prevention of non-union. $\mathrm{J}$ Bone Joint Surg Br. 1959; 41-B(1):122-131.

19. Dodge HS, Cady GW. Treatment of fractures of the radius and ulna with compression plates. J Bone Joint Surg Am. 1972; 54(6):1167-76.

20. Schemitsch EH, Richards RR. The effect of malunion on functional outcome after plate fixation of fractures of both bones of the forearm in adults. $J$ Bone JointSurgAm. 1992; 74(7):10681078.

21. Droll KP, Perna P, Potter J, Harniman E, Schemitsch EH, McKee MD et al. J Bone Joint Surg Am. 2007; 89(12):2619-24

22. Leung F, Chow SP. Locking compression plate in the treatment of forearm fractures' a prospective study. J Orthop Surg (Hong Kong). 2006; 14(3):291-4.

23. S Sharma, H Dang, V Sharma, S Sharma. Treatment of diaphyseal forearm bone fractures by Locking compression Plate (LCP)." The internet journal of orthopaedic surgery. 2009; 11:1.

24. Fernando Baldy dos Reis, Flavio Faloppa."Outcome of diaphyseal forearm fracture- nonunion treated by autologous bone grafting and compression plating" Annals of surgical innovation and research, 2009, 3:5.

25. Jesse.B.Jupiter; Reconstruction of post traumatic disorders of the forearm. JBJS (Am); Vol 91-A, Nov 2009, 2730-2737.

26. Sevitt Simon. Primary repair of fractures and compression fixation. Chap-10 in bone repair and fracture healing in man. Churchill Livingstone, Edinburgh, 1981, 145-156.

27. Colton C. History of Osteosynthesis. Chap-2 in AO/ ASIF Instruments and Implants, $2^{\text {nd }}$ ed, Texhammer R, C.Colton, Berlin, Springer Verlag, 1994, pp3.

28. Rush LV, Rush HL. A reconstructive operation for comminuted fractures of upper third of ulna. Am J surg 1937; 38:332.

29. Lambrunidi C. Intramedullary Kirshner Wires in the treatment of fractures proceedings of Royal Society of Medicine. 1939; 33:153.

30. Knight RA, Purvis GD. Fracture of both bones of forearm in adults. JBJS. 1949; 31-A;755-764.

31. Evans EM. Rotational deformity in the treatment of fracture of both bones of forearm. JBJS. 1945; 24:373379.
32. Eggers GWN. Internal Contact Splint. JBJS. 1948; 30A (1):40-52.

33. Perrens M, Allgower M, Brunner H, Burch HB, Cordey $\mathrm{J}$, Ganz R et al. The concept of biological plating using the limited contact dynamic compression plate. Injury. 1991; 22(1):1-41. 